Corrigendum

\title{
Corrigendum to "Numerical Solution of Nonlinear Fractional Volterra Integro-Differential Equations via Bernoulli Polynomials"
}

\author{
Emran Tohidi, ${ }^{1}$ M. M. Ezadkhah, ${ }^{2}$ and S. Shateyi ${ }^{3}$ \\ ${ }^{1}$ Department of Mathematics, Aligoudarz Branch, Islamic Azad University, Aligoudarz, Iran \\ ${ }^{2}$ Department of Applied Mathematics, School of Mathematical Sciences, Ferdowsi University of Mashhad, Mashhad, Iran \\ ${ }^{3}$ Department of Mathematics and Applied Mathematics, School of Mathematical and Natural Sciences, University of Venda, \\ P Bag X5050, Thohoyandou 0950, South Africa \\ Correspondence should be addressed to S. Shateyi; stanford.shateyi@univen.ac.za \\ Received 25 February 2015; Accepted 23 March 2015 \\ Copyright (C) 2015 Emran Tohidi et al. This is an open access article distributed under the Creative Commons Attribution License, \\ which permits unrestricted use, distribution, and reproduction in any medium, provided the original work is properly cited.
}

In the paper titled "Numerical solution of nonlinear fractional volterra integro-differential equations via Bernoulli polynomials" the affiliation of Stanford Shateyi was "Institute for Groundwater Studies, Faculty of Natural and Agricultural Sciences, University of the Free State, Bloemfontein 9300, South Africa" and is corrected as above. 


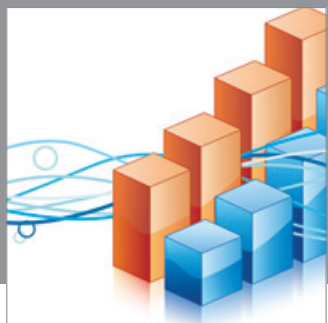

Advances in

Operations Research

mansans

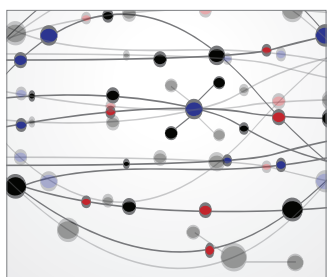

The Scientific World Journal
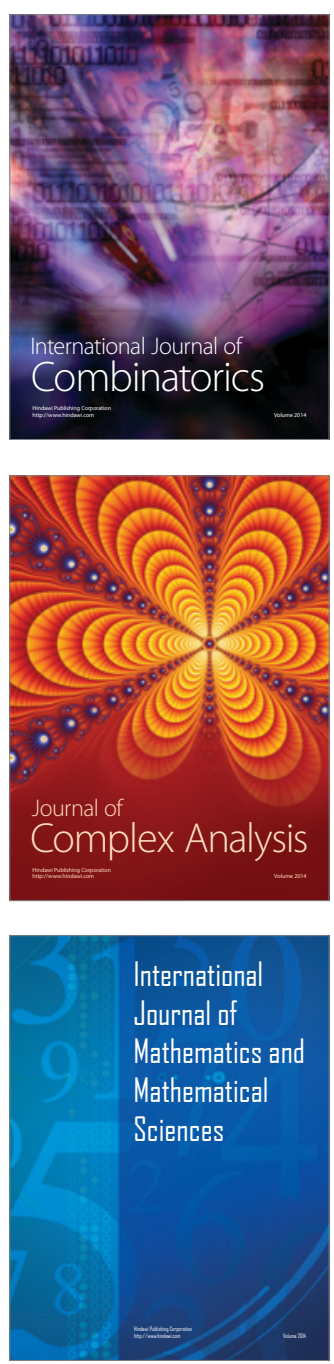
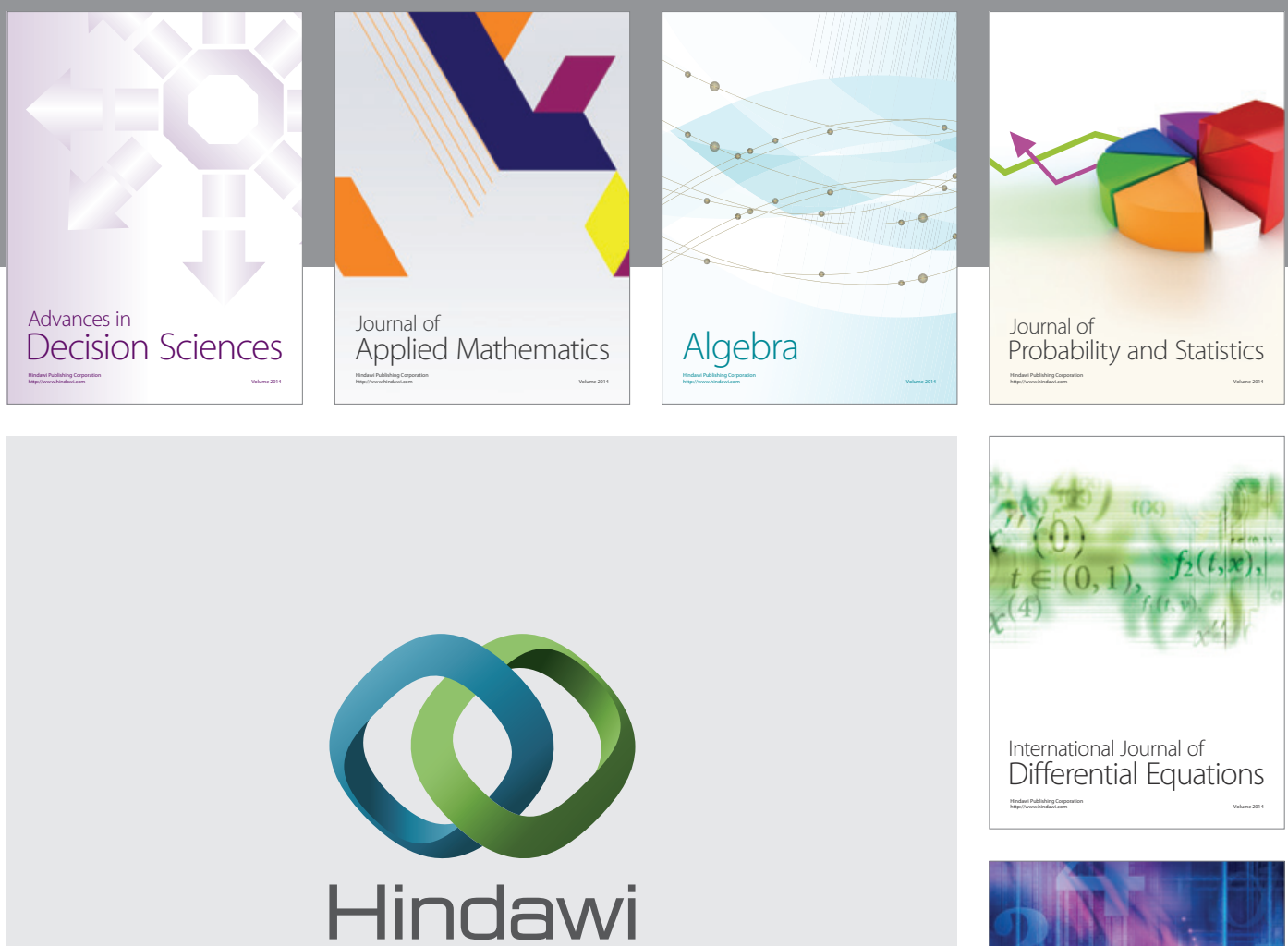

Submit your manuscripts at http://www.hindawi.com
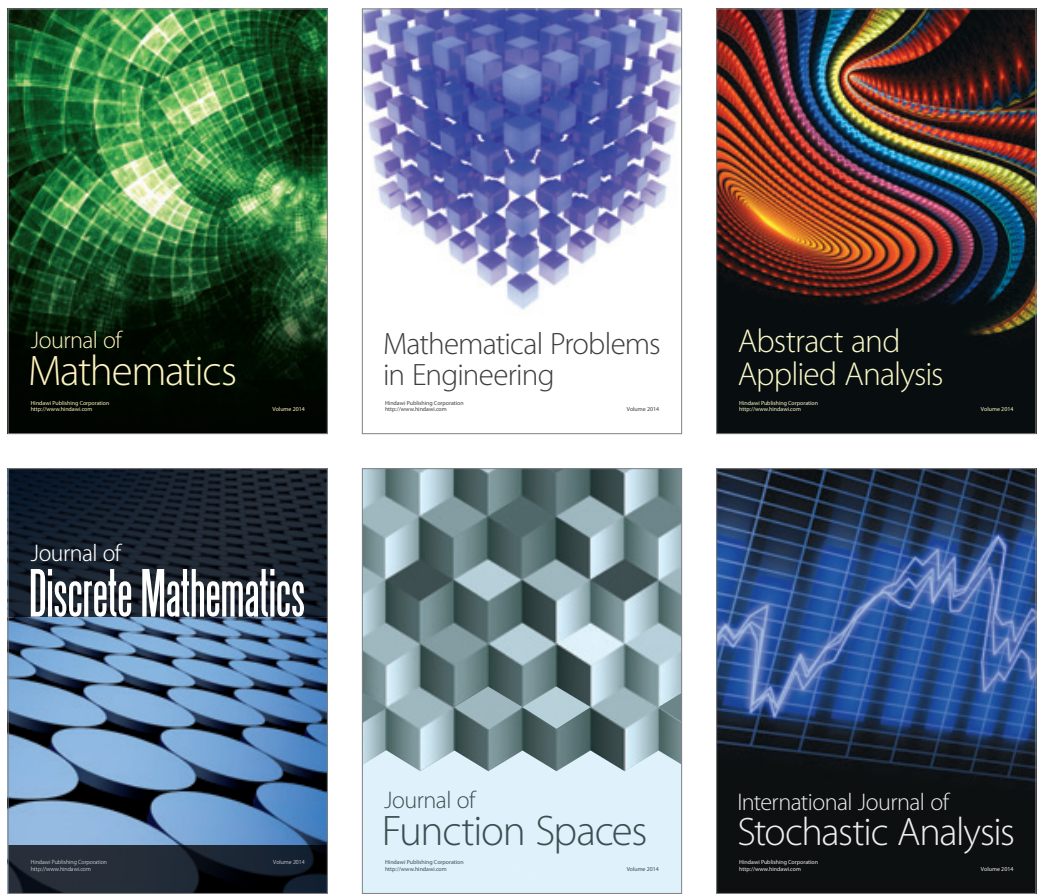

Journal of

Function Spaces

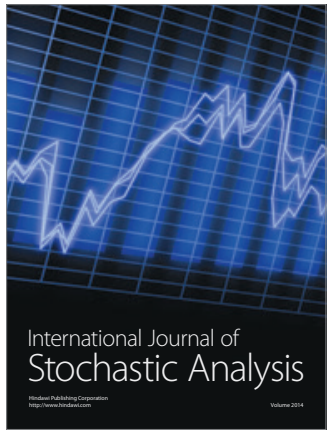

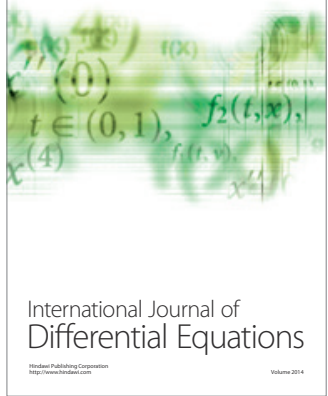
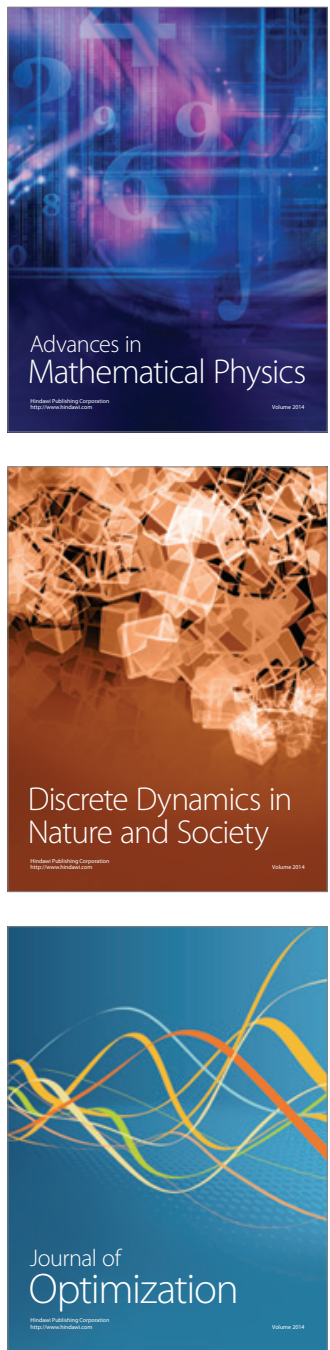